\title{
STRATEGIC FORESIGHT: TOWARDS ENHANCING LEADERSHIP CAPABILITIES AND BUSINESS SUSTAINABILITY
}

\author{
Baiba Dominiece-Diasa ${ }^{1}$, Ineta Portnova ${ }^{2}$, Tatjana Volkova ${ }^{3}$ \\ 1,2,3Department of Management,BA School of Business and Finance, K. Valdemara street 161, Riga, Latvia \\ E-mails: ${ }^{1}$ baiba.dominiece@gmail.com (corresponding author); ${ }^{2}$ ineta.portnova@gmail.com; \\ 3tatjana.volkova@ba.lv
}

\begin{abstract}
Organizations with well-developed strategic foresight capabilities have higher level awareness about the emerging pattern of external environment threats and opportunities and make better decisions to respond to these challenges. Scholars emphasise that even though topics on leadership and leadership capabilities have become increasingly popular, there is still little research on concepts and methods of "futures studies". Research purpose is to investigate the level of development of strategic foresight capabilities on the top management level in the drone industry and its application for ensuring long term business sustainability. Research methodology: a case study method and semi-structured interviews. The main results of the research show that the drone industry applies some strategic foresight capabilities which are not fully recognized and exploited systematically by the business leaders. Development and application of strategic foresight capabilities could be considered as a strategic priority in the industry.
\end{abstract}

Keywords: leadership, strategic foresight, futures, change management, capabilities, drone industry.

JEL Classification: M0.

\section{Introduction}

In the strategic management studies one of the most crucial question is what makes business successful and sustainable. The literature studies show that strategic foresight has great impact on business results. The scientific research of strategic foresight is rapidly developing; particularly methods, organising and experiences are the dominant topics (Iden, Methlie, \& Christensen, 2017) which are being researched by the scholars. Iden et al. (2017), while performing the systematic literature review of strategic foresight, have found out that there are some researchers who have tried to address the top management involvement and decision-making processes related to the strategic foresight. The same reflection is shared by Christensen (1997), stating that foresight is a vital for entrepreneurial actions since it is related to the ability to predict the inadequacies and opportunities in the market. Thus, the authors conclude that strategic foresight can be considered as one of the key leadership capabilities.

The concept of leadership is widely studied and there are many evidence for leadership essential role in decision-making and strategy and ability to adapt for changes and uncertainty (Bryman,
2013; Bass \& Stogdill, 1990; Rees \& Porter, 2015). To identify leadership strategic foresight capabilities, the dynamic capabilities theory has been applied. Dynamic capabilities are being viewed as primary factors for an organisation to adapt to the rapidly changing business environments (Castiaux, 2012). From leadership perspective leaders empower organization's dynamic capabilities. That highlights importance of understanding leadership capabilities for leading in uncertainty and complexity.

The rapidly growing Unmanned Aerial Vehicle or drone industry serves as a great example where leadership capabilities and strategic foresight is particularly important. Innovations that foster drone technology now are used in almost every industry starting from military, agriculture until entertainment (Giones \& Brem, 2017).

The purpose of the paper is to identify the level of development of strategic foresight capabilities in the drone industry and its application by top management for ensuring business sustainability. The authors look at strategic foresight as a leadership capability to enhance the strategic decision-making process. The research methodology is a case study and semi-structured interviews. This paper is considered as pilot study and findings will be used for future researches. 


\section{Unmanned aerial vehicle or drone industry}

Unmanned aerial vehicle or drone industry is a new but fast-growing industry. The first military drone was created in 1990s and many years drones were used for specific military targets. Massive changes began when drone technologies came into the commerce sector. Now drone technologies are considered as divers with various attributes and range in size, which varies from large and fast military drones to commercial micro drones (Clarke, 2014; Rao, Gopi, \& Maione, 2016). Common attribute is that drone does not have onboard human operator, they are autonomously or remotely operated (Rao et al., 2016). However, starting from 2000s industry began to develop dramatically and its application is very wide (Giones \& Brem, 2017). PricewaterhouseCoopers LLP forecast reflects that by year 2020 commercial market opportunity for drones will be 127 billion USD (Moskwa, 2016).

The emergence of a new industry brings along many issues for discussions and researches in society and for scientists. Luppicini and So (2016) have done systematic review of commercial drone literature. They have reviewed literature from 2010 to 2015 and identified eight main aspects from the following social perspectives: ethics, safety, law, privacy, air space, human vs machines, informational integrity, and commercial aspects. Findings advocate that "commercial drone use can improve lifestyle and increase efficiency, there is a need to invest more attention to possible negative and unknown consequences to facilitate the ethical use of commercial drones" (Luppicini \& So, 2016, p. 109). These results are in line with Rao et al. (2016) findings - in drone industry focus is needed on ethics, transparency and legality, safety, security, privacy, effectiveness, and regulation.

For further development of industry Giones and Brem (2017) highlight the need to increase reliability of technical part and ability to understand the industry drivers (in short and long run) to be able to identify and apply suitable business models. The environment in which drone technology evolves presents a lot of uncertainty and complexity that demands strategic focus and new combination of strategic foresight capabilities. However, the authors found only few studies about leadership capabilities enhancing the application of strategic foresight in the drone industry organizations.

\section{Strategic foresight and dynamic capabilities}

Strategic foresight is the ability to create and maintain a forward view (Rohrbeck, Battistella, \& Huizingh, 2015; Slaughter, 1999), sense the opportunities and improvements (Saarikko, Jonsson, \& Burström, 2014) and assist decision makers to shape the organisation's future course of action (Vecchiato, 2012; Slaughter, 1999). Conway (2005) even argues that strategic foresight is the core organisational capacity.

The dynamic capabilities, on the other hand, represent organisations ability to create competitive advantage for the future. Teece, Pisano, and Shuen (1997) have defined dynamic capabilities as "the firm's ability to integrate, build, and reconfigure internal and external competences to address rapidly changing environments".

According to van der Laan's (2008) literature review about strategic foresight, strategic leadership and strategic thinking the strategy consists of three stages - strategic thinking for strategy formulation (analysing, opportunity noticing, long term-view), strategic planning (resources, actions, time frame planning) and strategy implementation - put into operation).

Slaughter (1996), by describing the development of strategic foresight within companies, has identified five levels for foresight development:

- Level 1: Recognition - each individual has the foresight capacity;

- Level 2: Immersion - generation of futures discourse;

- Level 3: Methodologies - development and implementation of key methods;

- Level 4: Niches - foresight focus areas;

- Level 5: Sustainability - Long-term thinking.

In the literature two forms of capabilities can be found - operational and dynamic capabilities. Operational capabilities are considered as effective and efficient resources operation while dynamic capabilities allow an organization to look forward and develop successfully in the changing environment (Dixon, Meyer, \& Day, 2014). In this paper the authors are focusing on dynamic capabilities and its application to understand better the strategic foresight dynamic capabilities.

The main characteristics of the dynamic capabilities are sensing, seizing and transforming (Teece, 2007). In other words, that can be explained as firm's ability to identify and properly utilise the resources in the changing environment to create value for the business (Noori, Tidd, \& 
Arasti, 2012). Since these capabilities origin from Resource-based view (Barney, 1991) the authors create connections between resources and capabilities as both shall always interact. Conway (2005) emphasises that companies, during their strategy development activities, tend to miss out one crucial element - a foresight capacity. Conway argues that scenario planning methods are perceived to consider the future, however that does not lead firms to develop and sustain their foresight capabilities.

Slaughter (1996) has identified five levels of social foresight capacities which, the authors find, have a strong correlation to the organisational capacities. Social foresight capacities allows individual, social, cultural factors to come together in a set of relationships (Slaughter \& Bussey, 2005).

Based on Teece (2007), Barney (1991), Slaughter (1996) and Conway (2005), the authors have created Capabilities-Resources matrix which indicates what capabilities and resources firms need to exercise for achieving levels of foresight development.

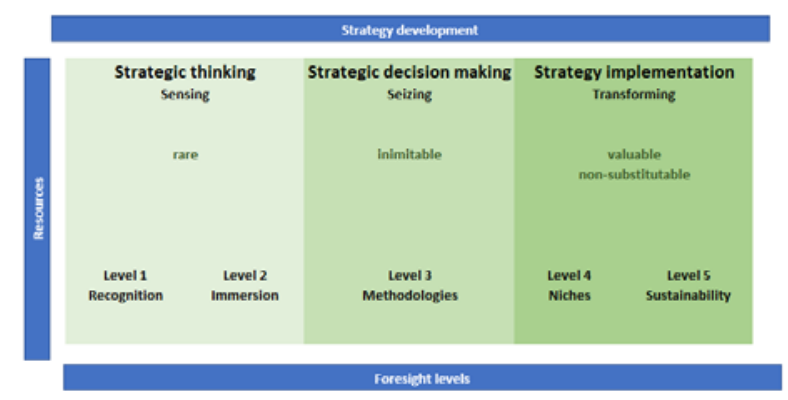

Figure 1. Capabilities-Resources matrix

Application of strategic foresight in an organisation is a time-consuming process, nevertheless, the leaders should invest enough time to develop this capability (Conway, 2005) to ensure a sustainable business development in the futures' changing environment. However, "top management's entrepreneurial and leadership skills around sensing, seizing, and transforming are required to sustain dynamic capabilities" (Teece, 2012). Therefor in the next section more detailed is analysed leadership capabilities.

\section{Leadership capabilities for strategic foresight}

To identify strategic foresight dynamic capabilities from leaders' perspective the authors reviewed literature that studied strategic foresight and leadership capabilities, as well leading in a complex and uncertain environment.
From leadership perspective, dynamic capabilities empower leaders to adapt organization to changing environment (Dixon, Meyer, \& Day, 2014; Teece, Pisano, \& Shuen, 1997). Teece (2007) highlights it as leaders' capacity to sense and shape opportunities/threats, and seize them in competitive way, transforming in new way. Hines (2002) also advocates that having capabilities for strategic foresight and innovation could be the most important capabilities for organization's competitive advantage. Foresight as the capability is related with creating and maintaining forward view which is in high-quality. This allows to predict emerging opportunities, trends and risks (Cornish, 2004; Rohrbeck et al., 2015). Capability results from long- term view, strategic thinking, sensory acuity, broadminded un business eco-system understanding (O'Brien \& Robert, 2009). Leadership capabilities for foresight defined by Cornish (2004) is the ability to create and maintain a qualitative forward view thus anticipating emerging opportunities and threats.

Opportunity identification in literature is identified as entrepreneurial alertness that is enhanced by information or recognises lack of knowledge and sees how could opportunities be used (Ray \& Cardozo, 1996). Rai and Cardozo (1996) argue that any type of opportunity identification or entrepreneurial alertness, is based on alertness that is enhanced by information. Both authors explain the entrepreneurial alertness as paying attention and being sensitive to the information about the objectives, events and behaviour patterns in the environment. Smith and DiGregorio (2001), however, stress that entrepreneurial alertness focuses on the ability to recognise pervasive knowledge deficiencies in the market and how could they be used as new business opportunities. Special focus is placed on the attention to the problems of producers and consumers, their currently unsatisfied needs and new combinations of available resources. Ray and Cardozo (1996) also suggest that the increasing of entrepreneurial alertness would most likely increase the possibility to identify opportunities. Vagnoni and Khoddami (2016) identify strategic foresight as a determinant of entrepreneurial alertness, and the ability to predict discreteness of commercial environments, market place, available threats and opportunities in the market as well as potential destructive movements of rivals.

Towards transforming or to enabling organizations to deal effectively with complex changes authors, have found evidence, that scholars recog- 
nize it as organizational adaptability; from leadership perspective, enabling the adaptive process through adaptive space (Uhl-Bien \& Arena, 2018). Leadership for organizational adaptability focuses on leaders' ability to lead organizations and the people and to be adaptive in complex challenges. Based on Uhl-Bien and Arena (2017) findings, ability to lead complex changes depends on leaders' capability to a) generate innovation, learning and development, b) transform innovation into new adaptive order to enhance outcomes, c) create adaptive space to ensure the ongoing viability.

According to Teece (2012), transforming is nonstop renewal or continued change management. From leadership perspective, it means directing the organisation toward change initiatives by transferring activities - dialogue, cooperation and learning (Salvato \& Vassolo, 2018). Transforming is combination of sensing, seizing with new capabilities because "many strategic actions and transformations require actions that one may never replicate" (Teece, 2012). In other words, transformation activities are placed in long term action knowledge, skills and resources obtained through sensing and seizing activities.

\section{Research methodology}

The drone industry in Latvia have relatively small number of companies, therefore authors are using case study method. The authors have found the case study method most suitable for this study, since the goal was to gain first insights of the strategic foresight and leadership capabilities in relation to the drone industry. The second target was to identify areas for future, more thorough research topis as well as to test the created interview questionnaire. The authors have acknowledged the scientific discussion, scepticism (Rowley, 2002) and limitations (Miles, 1979; Yin, 1984) on this methodology. Nevertheless, this method could be selected during delivering an exploratory phase of research project (Rowley, 2002), therefore the authors find this method useful for gaining insights in the drone industry. The authors are striving to determine the leaders' understanding of strategic foresight, motivation and abilities to apply strategic foresight in their organisation. This also corresponds to the advise of asking the "how" and "why" questions (Yin, 1984; Schell, 1992) about the current set of events. For this research the authors were following Yin's (1984) case study research model as this fits best to the research question and allows focus on current events in the drone industry.

To complement the case study method, the authors also used the semi-structured interview (Gill, Stewart, \& Treasure, 2008). This interview type was selected since the authors did have a set of topics pre-defined, based on research topic, however, the authors did not want to limit the respondents too much. The authors developed a set of 13 questions, which covered the main aspects of the Figure 1 Capabilities- Resources matrix. The authors held on-site interviews with representatives - two top-level managers of the company under research. It was decided not to present the respondents with the contents of Figure 1 or use any particular terms (e.g. strategic foresight or dynamic capabilities), which might mislead the course of the interview. The company was established at the end of 2009, in a business incubator, and today is one of the leading developers in the world for specific drone technology. The interview questions aimed to investigate whether the company's top leadership has established any strategic foresight routines and to what extent they are being used in the company. The authors also steered the questions in a way to identify the leadership strategic foresight capabilities and interest towards sensing the future trends, seizing opportunities and transforming the organization through enhancing, combining, protecting and reconfiguring company's tangible and intangible assets to reach the desired future outcomes.

\section{Results}

The semi-structured interviews results show that company has quite developed dynamic capabilities. Strategic thinking is seen as leadership capability and is the responsibly of the management team. Each leader is responsible for seeking novelty in his field on everyday bases. This group of leaders is responsible for the decision-making and implementation processes. There is no separate strategic leader or strategic planner. Drivers for novelty are customers, which are often also competitors, specialized literature and specialized exhibitions. The company has developed good worldwide network. Despite the world-wide coverage the market is small and they now all the players. Technology safety and reliability are mentioned as challenges for further development. Company's transformation is mainly based on customers' needs and satisfaction. Change management and transformation is managed on 
project bases. One third of the company's employees are involved in the product research and development. They have development plans for a 2 years period. However, involvement in policymaking are not considered as necessary skill as well as no special tools or systems are used for strategic foresight recognition and management.

Interview results reveal the the company under research belong to the Foresight Level 2. This means that the company has well developed strategic thinking capability as well as their resources are rare and thus also hardly inimitable. The company is able to sense the opportunities and successfully use them for their competitive advantage. Seizing capability is particularly important for the companies operating in the drone industry taking into consideration the industry's rapid development. There are number of competitors flowing into the market therefore it is crucial for the company to be able to seize their opportunities and use the wisely depending on their operating model. Nevertheless, the company does not focus on development of methods or tools directly related to the strategic foresight currently.

The company does not perceive the development of the strategic foresight as a core organisational capacity. They have established their own market research and evaluation methods which are particularly relevant to their industry and organisational management practices.

\section{Conclusions}

The main conclusions of the research paper is that particular player within the drone industry applies unintentionally some strategic foresight capabilities which are not fully recognized and exploited systematically and systemically. The conducted case study highlights low level of awareness of strategic foresight by top management, existing types, tools and methods of strategic foresight. The company analysed does not see the necessity to engage in a more systematic approach towards developing systematic strategic foresight methods and tools which could be explained by the fact that top management doesn't posess the necessary leadership capabilities in strategic foresight. Thus further, more extensive research is required to understand underlying implications of strategic foresight wider applications by top management towards ensuring the business sustainability. This case study indicates further research areas, such as leaders' motivation to understand, develop, integrate and use strategic foresight methods and tools. Another research area could be the comparison of the start-up companies (within the drone industry) which have emerged from business incubators with those having rich heritage. The authors of this research paper will further look at the drivers of identified leadership strategic foresight capabilities.

The Capabilities-Resources matrix, developed by the authors, shall serve as a guide for the future researches as it can assist in structuring the results and detecting correlation between strategic foresight capabilities and business performance.

The paper has limitation - used case study method that provide opportunity to research limited number of companies. In further researches is necessary to increase the number of investigated objects. This research paper addresses the company based in Latvia.

\section{Disclosure statement}

Authors are required to include a statement at the end of their article to declare whether or not they have any competing financial, professional, or personal interests from other parties.

\section{References}

Barney, J. B. (1991). Firm resources and sustained competitive advantage. Journal of Management, 17(1), 99-120. https://doi.org/10.1177/014920639101700108

Bass, B. M., \& Stogdill, R. M. (1990). Bass \& Stogdill's handbook of leadership: theory, research, and managerial applications. Simon and Schuster.

Bryman, A. (2013). Leadership and organization. Routledge.

Castiaux, A. (2012). Developing dynamic capabilities to meet sustainable development challenges. International Journal of Innovation Management, 16(6). https://doi.org/10.1142/S1363919612400130

Conway, M. (2005). Strategic planning revisited: a futures perspective in world futures society annual conference. Chicago, U.S.A.

Christensen, C. M. (1997). The innovator's dilemma: when new technologies cause great firms to fail. Cambridge, MA: Harvard Business School Press.

Clarke, R. (2014). Understanding the drone epidemic. Computer Law and Security Review, 30(3), 230-246. https://doi.org/10.1016/j.clsr.2014.03.002

Cornish, E. (2004). Futuring: the exploration of the future. World Future Society, U.S.A.

Dixon, S., Meyer, K., \& Day, M. (2014). Building dynamic capabilities of adaptation and innovation: a study of micro-foundations in a transition economy. Long Range Planning, 47(4), 186-205. https://doi.org/10.1016/j.lrp.2013.08.011

Gill, P., Stewart, K., \& Treasure, E. (2008). Methods of data collection in qualitative research: interviews and focus groups. British Dental Journal, 204(6), 291-295. https://doi.org/10.1038/bdj.2008.192 
Giones, F., \& Brem, A. (2017). From toys to tools: the coevolution of technological and entrepreneurial developments in the drone industry. Business Horizons, $60(6), 875-888$.

https://doi.org/10.1016/j.bushor.2017.08.001

Hines, A. (2002). A practitioner's view of the future of futures studies. Futures, 34(3-4), 337-347. https://doi.org/10.1016/S0016-3287(01)00048-9

Iden, J., Methlie, B. L., \& Christensen, E. G. (2017). The nature of strategic foresight: a systematic literature review. Technological Forecasting and Social Change, $116,87-97$. https://doi.org/10.1016/j.techfore.2016.11.002

Luppicini, R., \& So, A. (2016). A technoethical review of commercial drone use in the context of governance, ethics, and privacy. Technology in Society, 46, 109119. https://doi.org/10.1016/j.techsoc.2016.03.003

Meyer, B. Ch. (2001). A case in case study methodology. Field Methods, 13(4), 329-352. https://doi.org/10.1177/1525822X0101300402

Miles, B. M. (1979). Qualitative data as an attractive nuisance: the problem of analysis. Administrative Science Quarterly, 24(4), 590-601. https://doi.org/10.2307/2392365

Moskwa, W. (2016). World drone market seen nearing $\$ 127$ billion in 2020, PwC says. Retrieved from https://www.moneyweb.co.za/news/tech/world-dronemarket-seen-nearing-127bn-2020-pwc-says/

Noori, J., Tidd, J., \& Arasti, M. R. (2012). Dynamic capability and diversification. In Series on Technology Management: Vol. 19, J. Tidd (Ed.). From Knowledge Management to Strategic Competence - Assessing Technological, Market and Organisational Innovation.

O'Brien, E., \& Robertson, Ph. (2009). Future leadership competencies: from foresight to current practice. Journal of European Industrial Training, 33(4), 371-380. https://doi.org/10.1108/03090590910959317

Ray, S., \& Cardozo, R. (1996). Sensitivity and creativity in entrepreneurial opportunity recognition: a framework for empirical investigation. The Sixth Global Entrepreneurship Research Conference. Imperial College, London.

Rao, B., Gopi, A. G., \& Maione, R. (2016). The societal impact of commercial drones. Technology in Society, 45, 83-90. https://doi.org/10.1016/j.techsoc.2016.02.009

Rees, W. D., \& Porter, C. (2015). Skills of management and leadership, managing people in organizations. Palgrave. Macmillan Education.

Rohrbeck, R., Battistella, C., \& Huizingh, E. (2015). Corporate foresight: an emerging field with a rich tradition. Technological Forecasting and Social Change, 101, 19. https://doi.org/10.1016/j.techfore.2015.11.002

Rowley, J. (2002). Using case studies in research. Management Research News, 25(1), 16-27. https://doi.org/10.1108/01409170210782990
Saarikko, T., Jonsson, K., \& Burström, T. (2014, June). Towards an understanding of entrepreneurial alertness in the formation of platform ecosystems. 22nd European Conference on Information Systems (ECIS). Tel Aviv, Israel.

Salvato, C., \& Vassolo, R. (2018). The sources of dynamism in dynamic capabilities. Strategic Management Journal, 39(6), 1728-1752.

Schell, Ch. (1992). The value of the case study as a research strategy. Manchester business school. Retrieved from http://www.finance-mba.com/Case\%20Method.pdf

Slaughter, R. (1996). Future studies: from individual to social capacity. Futures, 28(8), 751-762. https://doi.org/10.1016/0016-3287(96)00009-2

Slaughter, R. (1999). Futures for the third millenium: enabling the forward view. Prospect.

Slaughter, R., \& Bussey, M. (2005). Futures thinking for social foresight. Tamkang University Press.

Smith, K. G., \& DiGregorio, D. (2001). The role of entrepreneurial action in the market process. Unpublished manuscript, University of Maryland.

Teece, D. J., Pisano, G., \& Shuen, A. (1997). Dynamic capabilities and strategic management. Strategic Management Journal, 18(7), 509-533. https://doi.org/10.1002/(SICI)1097-0266(199708) 18:7<509::AID-SMJ882>3.0.CO;2-Z

Teece, D. J. (2007). Explicating dynamic capabilities: the nature and microfoundations of (sustainable) enterprise performance. Strategic Management Journal, 28(13), 1319-1350. https://doi.org/10.1002/smj.640

Teece, D. J. (2012). Dynamic capabilities: routines versus entrepreneurial action. Journal of Management Studies, 49(8), 1395-1401. https://doi.org/10.1111/j.1467-6486.2012.01080.x

Uhl-Bien, M., \& Arena, M. (2018). Leadership for organizational adaptability: a theoretical synthesis and integrative framework. The Leadership Quarterly, 29(1), 89104. https://doi.org/10.1016/j.leaqua.2017.12.009

Uhl-Bien, M., \& Arena, M. (2017). Complexity leadership: enabling people and organizations for adaptability. Organizational Dynamics, 46(1), 9-20. https://doi.org/10.1016/j.orgdyn.2016.12.001

Vagnoni, E., \& Khoddami, S. (2016). Designing competitivity activity model through the strategic agility approach in a turbulent environment. Foresight, 8I(6), 625-648. https://doi.org/10.1108/FS-03-2016-0012

Van der Laan, L. (2008). The imperative of strategic foresight to strategic thinking. Journal of Futures Studies, 13(1), 21-42.

Vecchiato, R. (2012). Strategic foresight and environmental uncertainty: a research agenda. Foresight 14(5), 387400. https://doi.org/10.1108/14636681211269879

Yin, R. K. (1984). Case study research: design and methods. Newbury Park: Sage Publications. 